\title{
Mitteilungen des Magnesium- und Osteoporoseforums Bad Radkersburg
}

J. Miner. Stoffwechs. Muskuloskelet. Erkrank. 2017 · 24:133 https://doi.org/10.1007/s41970-017-0009-y

c) Springer-Verlag GmbH Austria 2017
Ärztliche Arbeitsgemeinschaft für Lebensstilmedizin p.a. Prim. Dr. Bernd ZIRM (V.i.S.d.P.)

8490 Bad Radkersburg -

VITAMED Gesundheitszentrum, Alfred-Merlini-Straße 7

Tel.: 03476/3403

Fax: 03476/3403

Homepage: www.lebensstil-medizin.at

E-Mail: bernd.zirm@gmx.at
Liebe Kolleginnen!

Liebe Kollegen!

Wir haben am 15.09.2017 das neue Gesundheitszentrum Vita med eröffnet. Mit 02.10.2017 sind auch die Ordinationen voll in Betrieb. Wir freuen uns weiters, ein Institut für Lebensstilmedizin zur Verfügung zu haben, welches mit Kur- und Vorsorgepatienten in Zukunft interessante Entwicklungen studieren wird, insbesondere spielen hier der Mineralstoffwechsel und Stress in Zukunft eine wesentliche Rolle.

Ich darf Ihnen für die zukünftigen Feiertage alles Gute wünschen!

Mit kollegialen Grüßen aus der Südoststeiermark!

Prim. Dr. Bernd Zirm und sein Team

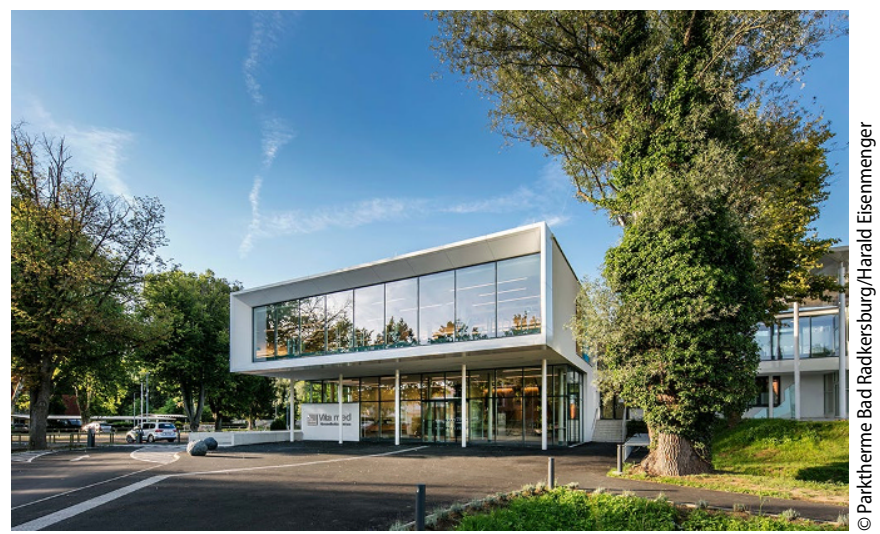

Hier steht eine Anzeige. 